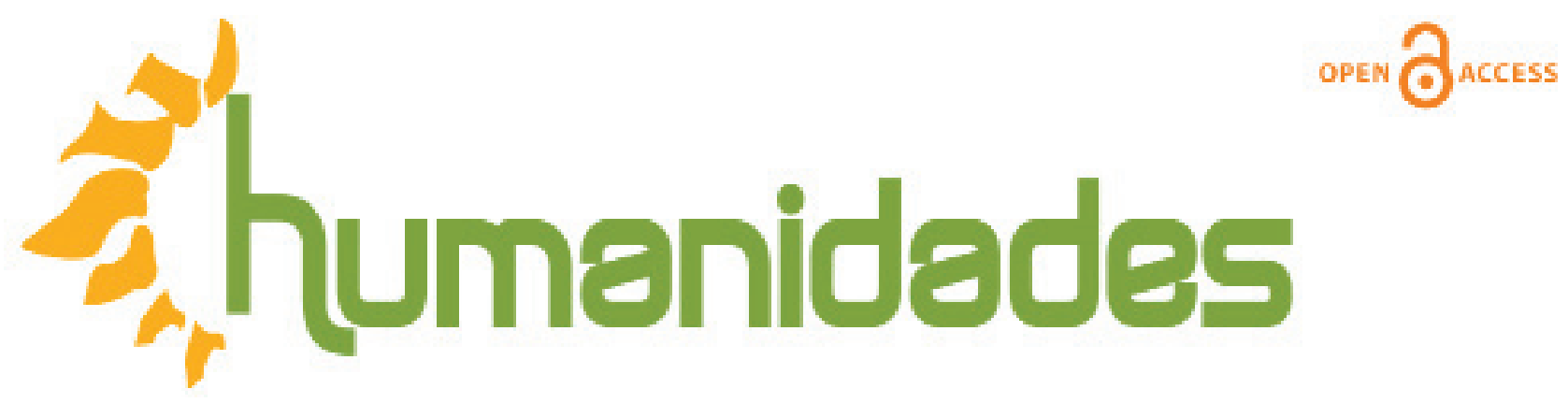

Revista de la Escuela de Estudios Generales, Universidad de Costa Rica

Julio-diciembre, 2018 • Volumen 8, número 2 • EISSN 2215-3934 • pp. 1-4

Recibido: 23-Mayo-2018 Aceptado: 23-Mayo-2018

\title{
País de agua, obra de Marisol Gutiérrez Rojas
}

DOI: https://doi.org/10.15517/h.v8i2.33402

\section{Lic. Rodolfo Arias Formoso}

Escritor, profesor de informática de la Universidad de Costa Rica, Costa Rica.

Correo electrónico: rodolfo.arias@.ucr.ac.cr

Todos los derechos reservados. Universidad de Costa Rica. Esta revista se encuentra licenciada con Creative Commons. Reconocimiento-NoComercial-SinObraDerivada 3.0 Costa Rica. Correo electrónico: humanidades@ucr.ac.cr/ Sitio web: http: //revistas.ucr.ac.cr/index.php/ humanidades 


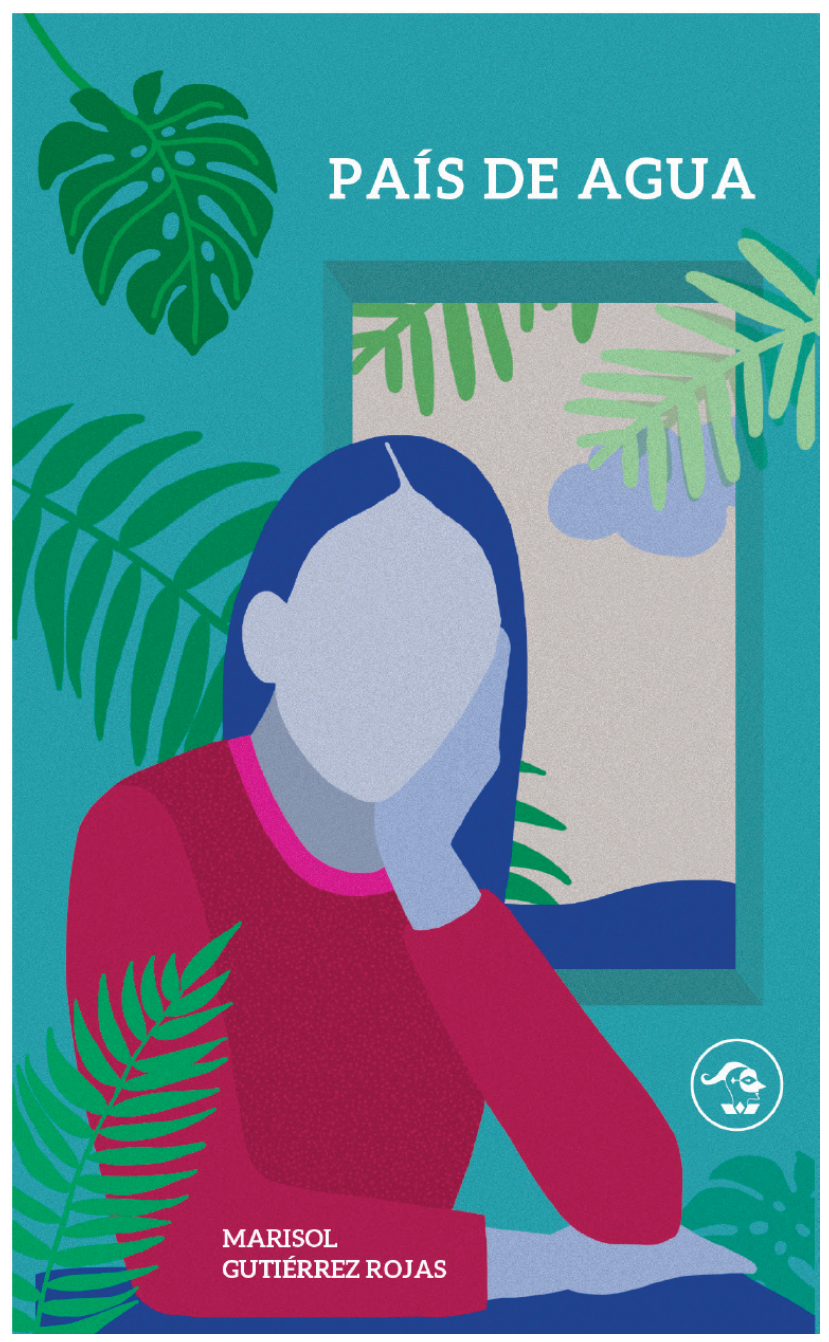

Marisol Gutiérrez Rojas

País de agua

Editorial Arlekin, 2018 
Recorrer las páginas de "País de agua", la primera colección de relatos breves que Marisol Gutiérrez ha querido compartir esta noche con nosotros y con todos quienes tengan el placer de leerla en lo sucesivo, es adentrarse, en efecto, en un mundo líquido. Un territorio sin piso firme, sin asideros perpetuos, sin referencias ni rumbos, visibles en el cielo o trazados en la piel.

Es irse encontrando, página tras página, con la persistencia de los ríos, con el quieto pero acezante carácter de los lagos, con el autoritario regaño de la lluvia. Es detenerse, como quien se topa en soledad con una sombra que no es la suya, frente al constante gotear del tiempo.

Es aceptar, conforme va uno percibiendo las texturas y los frugales encuadres del relato, que las palabras más fuertes, que las expresiones más drásticas, que los enojos más explosivos, son justamente lo que no está escrito. Está la palabra abuela, y la palabra silla y la palabra corredor. Y está la imagen de la vieja sentándose a esperar la muerte. Pero no está la palabra vendaval. No, porque esa no es la voz de la narradora. Aunque el vendaval esté desde las primeras líneas, cuando se nos diga que ella, la abuela, fue una mujer dura, de manos grandes y rodillas firmes. Una mujer hecha desde ella, y para ella. Para enfrentarla y resistirla: a la tempestad.

Quiero decir, con esto, que si bien los cuentos de Marisol transcurren entre cataclismos, revoluciones y diásporas, es con pausa y minucia que deberán ser leídos. Habrá uno de detenerse frente a campanas que convocan fantasmas, habrá uno de entender que ellas ya no están allí pero sí su tañido incesante. Intermitente, casi esporádico, pero incesante. Y habrá uno de saber que esas campanas, esa iglesia, esa calle, ya no están ahí, frente a los ojos, sino aquí, en los desvanes del alma. Aquí, donde el terremoto no terminará nunca.

No terminará, porque algunos dolores son inmunes a las distancias, y así se afirma página tras página en este pequeño gran libro. Resistentes a las fracturas, a las injusticias, a la coexistencia de lenguajes, vestimentas, privilegios y apellidos, desde mundos opuestos que comparten el mismo techo. El de doña Tachi, que tiene noventa y nueve años de mandar y de ser servida, y el de Luz y Aurora, que llevan casi ese mismo tiempo obedeciéndola y sirviéndola. 
Es, la de Marisol, una pluma que en primera instancia nos podría dejar una impresión de cautela, de comedimiento. Y como con un ritmo ideado para la confidencia, para el trasiego en voz baja de sucesos barridos bajo la alfombra de los buenos modales. Pero sólo en primera instancia. Si la dejamos trazar y seguir trazando, la autora desde su casi férrea parquedad nos lo mostrará todo. Y mostrará, al cabo, cuán responsable ha sido de cada palabra que ha escrito, cuánto las ha querido a todas y a cada una de ellas, las que forman sus tramas, describen sus paisajes, delinean a sus personajes, ahondan en sus penas, encuentran sus nombres justos, se adentran en sus sueños, se asoman curiosas en sus secretos.

Lo anterior me lleva a una reflexión final. Este es un libro hecho con un cuidado extremo. Aquí se ha preferido la toma de una fotografía en el momento preciso a la filmación exhaustiva de los sucesos. Se ha optado por poner unos alfileres con cabezas de colores en el mapa de la añoranza, y mirar los polígonos resultantes y recorrer los territorios demarcados, pero desde esos bordes, y sin rellenar los interiores. Esa tarea, con toda claridad, nos queda de encargo a los lectores. Y Marisol, con sus buenas maneras y su delicada persuasión, nos invita a hacerlo.

Lo hace, y perdóneseme la reiteración, al modo del agua. El agua que, como bien se afirma en la filosofía taoísta, es capaz de llegar hasta donde quiera, por estrecha que sea la grieta o por dura que sea la piedra. Y sin gritar, sin confrontar, sin herir. Usando de cauce para su destino final, que es el cielo del agua -el mar, soy obviocualquier superficie propicia: un cabello desde el cual chorrea, unas huellas que le abren paso, unos ojos que la dejan ir, unas mejillas que le permiten resbalar. 